\title{
Rift Valley fever in Kruger National Park: do buffalo play a role in the interepidemic circulation of virus?
}

Brianna R. Beechler ${ }^{1}$, Roy Bengis7, Robert Swanepoel6, Janusz T. Paweska², 8, Alan Kemp², Petrus Jansen van Vuren², Jenny Joubert ${ }^{5}$, Vanessa O. Ezenwa ${ }^{3}$ and Anna E. Jolles ${ }^{4}$

1 Corresponding Author Brianna Beechler, Oregon State University, College of Veterinary Medicine, 200 Magruder Hall, Corvallis OR 97331 USA

Email: beechleb@onid.orst.edu

2 National Institute for Communicable Diseases, Centre for Emerging and Zoonotic Diseases, Special Viral Pathogens Laboratory, Sandringham, 2131 South Africa

3 University of Georgia, Odum School of Ecology and Department of Infectious Diseases, College of Veterinary Medicine, Athens GA 30602, USA

4 Oregon State University, College of Veterinary Medicine, 200 Magruder Hall, Corvallis OR 97331, USA

5 Kruger National Park, Veterinary Wildlife Services, Skukuza, 1350 South Africa 6 University of Pretoria, Department of Medical Virology, Zoonoses Research Unit, South Africa. 7 South African State Veterinary Services, Kruger National Park Division, Skukuza 1350, South Africa 8 University of the Witwatersrand, School of Pathology, Division Virology and Communicable Disease Surveillance, Johannesburg, South Africa 


\begin{abstract}
Rift Valley fever (RVF) is a zoonotic mosquito-borne virus disease of livestock and wild ruminants that has been identified as a risk for international spread. Typically the disease occurs in geographically limited outbreaks associated with high rainfall events, and can cause massive losses of livestock. It is unclear how RVF virus persists during interepidemic periods but cryptic cycling of the virus in wildlife populations may play a role. We investigated the role that free-living African buffalo (Syncerus caffer caffer) might play in interepidemic circulation of the virus, and looked for geographic, age and sex patterns of RVFV infection in African buffalo. Buffalo serum samples were collected $(n=1,615)$ in Kruger National Park, South Africa during a period of 1996 to 2007 and tested for antibodies to RVF. We found that older animals were more likely to be seropositive for antiRVFV antibody than younger animals, but sex was not correlated with the likelihood of being anti-RVFV antibody positive. We also found geographical variation within KNP; herds in the south were more likely to have acquired anti-RVFV antibody than herds farther north - which could be driven by host or vector ecology. In all years of the study between 1996 and 2007 we found young buffalo (under 2 years of age) that were seropositive for antiRVFV antibody, with prevalence ranging between 0 and 27\% each year, indicating probable circulation. In addition, we also conducted a 4 year longitudinal study on 227 initially RVFV seronegative buffalo to look for evidence of seroconversion outside known RVF outbreaks within our study period (2008-2012). In the longitudinal study we found 5 individuals that seroconverted from anti-RVFV antibody negative to anti-RVFV antibody positive, outside of any detected outbreak. Overall, our results provide evidence of long-term undetected circulation of RVFV in the buffalo population.
\end{abstract}

\title{
Introduction
}

Rift Valley fever virus (RVFV; Bunyaviridae: Phlebovirus) is a zoonotic pathogen transmitted by mosquitoes and capable of infecting a wide variety of mammals. The virus causes outbreaks of disease in domestic ruminants characterized by death of newborn animals and abortion in pregnant sheep, goats and cattle (Swanepoel and Coetzer, 2004). Humans become infected through contact with the tissues of infected animals or via a mosquito bite. Large outbreaks occur at irregular intervals during years when heavy rains favor breeding of the mosquito vectors (Swanepoel and Coetzer, 2004). The virus was discovered in Kenya in 1930 (Daubney and Hudson, 1931), and was initially recorded only 
in sub-Saharan Africa, but from 1977-2007 it spread to Egypt, Mauritania, Madagascar, the Arabian Peninsula and the island of Mayotte (Pepin et al 2010). In southern Africa, focal or large-scale epidemics occur in a variable temporal cycle of between 7 and 11 years with these outbreaks usually occurring in the mid- to late summer months when rainfall is at its peak (Swanepoel \& Coetzer, 2004). It is unclear how RVF virus persists during the interepidemic periods, but two theories exist, namely long term survival in mosquito eggs infected via vertical transmission and cryptic cycling in as yet undetermined hosts (Chevalier et al, 2010; Chevalier et al, 2004). In 1996, neutralizing antibodies to RVFV were found in the sera of yearling buffalo from the Kruger National Park (KNP) on the northeastern border of South Africa, implying that there had been recent virus activity in the park (PG Howell, University of Pretoria, personal communication, 1996). After heavy rains in January 1999, RVFV was isolated from 6 aborted buffalo fetuses from pens adjacent to Skukuza Camp, KNP, where buffalo free of foot-and-mouth disease virus were being reared, and also from a waterbuck found dead $100 \mathrm{~km}$ northwest of Skukuza in Klaserie Nature Reserve, which is not fenced off from the KNP (NICD, unpublished laboratory records, 1999). The last known occurrence of RVFV on the inland plateau of South Africa had been recorded 23 years previously during a major outbreak in 1974-1976 (Barnard and Botha, 1977), but isolation of the virus from mosquitoes during an inter-epidemic period in 1971 and again from mosquitoes and cattle in a small outbreak on the coast of KwaZulu Natal Province in 1981, suggested that RVFV circulates endemically on the eastern seaboard of the country where the warmer and moister climate is more favorable to mosquitoes (McIntosh, 1972; Jupp et al, 1983).

KNP is contiguous to the coastal plain of Mozambique, with a warm and humid climate that is potentially favorable for RVFV circulation. This prompted us to investigate the persistence of RVFV in the park. Specifically, we used 1,615 serum samples collected opportunistically by the State Veterinary Services in KNP during bovine tuberculosis (BTB) prevalence studies spanning a 10-year period (1996-2007) to estimate RVFV seroprevalence in African buffalo, to evaluate age, sex and geographic patterns of RVFV infection in this species and to seek evidence of interepidemic circulation. We also used a longitudinal dataset from 227 buffalo sampled every six months between 2008-2012 to investigate the incidence of RVFV infection in buffalo over this period.

\section{Materials and Methods}


Study area. The KNP lies between 22.5 and $25.5^{\circ} \mathrm{S}, 31.0$ and $31.57^{\circ} \mathrm{E}$ and is 19,485 $\mathrm{km}^{2}$ in extent, but the area available to wildlife has effectively doubled during the past two decades by the removal of fences with private nature reserves to the west, and along the border with Mozambique to the east to form the Great Limpopo Transfrontier Park. It has one wet season per year with summer rainfall (November-April) ranging north to south from 400-700 mm per year. Rift Valley fever outbreaks typically occur towards the end of this wet season (Swanepoel and Coetzer, 2004). KNP is located at an average altitude of 250 $\mathrm{m}$ (range 200-900 m) above sea level with granitic soils to the west and basaltic soils to the east. The vegetation consists of predominantly mopani (Colophospermum mopane) woodland in the north and knobthorn-marula (Acacia nigrescens-Sclerocarya birrea) savannah in the south. It has a population of about 200,000 bovids the size of impala (Aepyceros melampus) and larger, including 37,000 African buffalo (Syncerus caffer caffer), and lesser numbers of smaller antelope (Kruger National Park Biodiversity Statistics, 20102011). ВTВ seroprevalence studies were conducted throughout the park, but the longitudinal portion of this study was restricted to the southern portion of KNP, in the Crocodile Bridge and Lower Sabie sections. The Crocodile Bridge section is along the southeastern boundary of the park, and much of it lies along the Crocodile River. The Lower Sabie section is just north of the Crocodile Bridge section and lies around the Sabie River.

Sample collection. Blood samples were collected from 1,615 buffalo in lethal (sacrificial) and non-lethal bovine tuberculosis prevalence surveys in 1996, 1998, 1999, 2005, 2006 and 2007, with a large fraction of the buffalo (590) captured in 1998 (see Table 1 for sample sizes). Capture locations were targeted (not randomly selected) for the tuberculosis survey (Figure 1; Table 1), but animals captured each day were randomly selected. Sex and age were determined for each animal. Age was estimated based on emergence of incisor teeth and horn size (Sinclair, 1977). The date and GPS coordinates were also recorded at each capture event. In addition to the survey data, serum samples from 227 radio-collared female buffalo from the southern portion of the park (initial mean age 3.5 years), which had been immobilized and re-bled every six months from 2008-2012, were used to monitor incidence of RVF infection. Any animal that died during the study period was replaced by a similarly aged animal to maintain a constant sample size of 200 individuals at each recapture. Over the 4-year period 227 initially seronegative buffalo were monitored. Serum harvested from clotted blood was stored at -70C until tested for neutralizing antibody to RVFV as described previously (Paweska et al, 2003). The virus 
neutralization test used here is considered to be the gold standard for Rift Valley fever serodiagnostics; therefore it has a presumed sensitivity and specificity of near $100 \%$ (Swanepoel \& Coetzer, 2004; Pepin et al, 2010); or as demonstrated by analysis of 955 bovids and 1,473 sheep serum samples collected from RVF free countries, where no false positives were identified (NICD, unpublished data).

Statistical analysis. Only the 1998 parkwide survey data, as the data for other years had limited distributions, were used to evaluate whether RVF seroprevalence was correlated with geographic location (Figure 1). For geographic location analyses, the park was divided into 3 broad areas noted as south, central and north to represent the rainfall gradient seen in the park with rainfall higher in the south than north (Venter et al, 2003). These areas were divided for analysis by the large permanent rivers of the region, which conveniently divide the park into 3 regions and somewhat restrict buffalo movement. Data was assessed for normality and equal variance using a Shapiro-Wilks normality test. The relationship between herd-level prevalence of antibody to RVF in the 1998 survey and geographic location was evaluated using an ANOVA with a Tukey's post-hoc test. A generalized linear model (GLM), with binomial distribution and logit link function, was used to evaluate whether site of capture (Crocodile Bridge or Lower Sabie) was correlated with an individual's likelihood of being seropositive for RVF in the longitudinal study. Age at capture was included as a covariate in the GLM to account for the potential effects of varying age distributions on any geographical pattern.

To evaluate whether demographic traits of 1,486 buffalo sampled between 19962007, was associated with anti-RVFV antibody status, we used a GLM with binomial distribution and logit link to test the effect of age and sex on individual serostatus. Year and location of capture were included as covariates. Since our data on year and capture location are non-independent the variables were included in the model solely to account for their potential effects on individual serostatus. All GLM output is included in table 2 including the estimate, $\mathrm{Z}$ value and $\mathrm{p}$ value. The estimate is the natural log of the odds ratio, while the $\mathrm{Z}$ value is from a likelihood ratio test. To differentiate between undetected large-scale epidemics or small-scale interepidemic cycling, a similar model was used to assess whether year/geographic location was associated with anti-RVFV antibody status of animals between 0.5 and 1 year of age, using all calf samples collected in all regions between 19962007. If the calves were indicative of one undetected large-scale epidemic we would expect cases to be clustered in space (geographic location) or time (year), but if the cases were 
spread out over time and space we would expect the calf cases to show no associations with geographic location or year. Buffalo $<6$ months old were excluded, as it is possible that antibody in this age group could be maternally derived. For calves of female animals naturally infected with RVFV virus maternal antibody usually persists until 3-4 months of age (Geering et al, 2002), and in sheep it wanes by 2 months (Zeller et al, 1997). There is no RVFV specific data for buffalo, but maternal immunity to other viral infections in buffalo lasted to a median of 3-5 months of age and no longer than 7 months at the extreme high end (Singh et al, 1967; Thomson; 1996; Hamblin and Hedger, 1978).

All statistical analyses were performed using the computer package R (R Core Development Team). For all analyses a p-value of less than 0.05 was considered statistically significant. Maps of the capture locations and herd RVFV serological status were prepared using ArcView GIS 9 (Figure 1).

Ethics Statement. This project was registered with the Scientific Services Projects Committee of the South African National Parks Board (SANparks), and received ethical clearance from the SANparks Animal Use and Care Committee. As an official project of the State Veterinary Services, it was automatically cleared in terms of the requirements of Section 20 of the Animal Diseases Act No. 35 of 1984. The Animal Care and Use Committees at Oregon State University and University of Georgia also approved the portion of the study involving the longitudinal monitoring of buffalo.

\section{Results}

A larger percentage of herds in the south and central regions were seropositive for antibodies to RVFV compared to herds in the North (Figure 1), and based on the 1998 parkwide data, herd level prevalence differed significantly among the 3 regions of the KNP $(F(2,25)=3.386, p=0.05$; Figure 2$)$. A Tukey's post hoc test showed that prevalence was lower in the North than in the South or Central regions (South vs. Central no difference; South vs. North mean difference $7.45 \%$, p $<0.05$; Central vs. North mean difference $6.94 \%$, $\mathrm{p}<0.05)$.

In examining factors associated with individual RVFV serological status across all buffalo captured between 1996-2007, and accounting for variation in sample year and geographic location, it was found that there was no correlation with sex of the animals while age was positively associated with serostatus, such that older animals were more likely to have antibody to RVFV (Table 2a \& Figure 3). For every unit increase in age (1 
year) the odds of being seropositive for RVF increase by a factor of 1.16 . In examining the dataset for calves $<1$ year of age to look for evidence of recent infection, it was found that animals between 0.5 and 1 year of age were infected at each survey time point except during the 2006 and 2007 surveys in the North (Figure 4). However, neither geographic location nor year were correlated with RVFV serological status in calves (Table 2b).

During the 2008-2012 longitudinal study, five of 227 seronegative buffalo seroconverted, for a total incidence rate of $2.2 \%$, or an annual incidence rate of $1-3 \%$. Of the five seroconverters, three occurred in the 2008/2009 wet season, and one each in the following two wet seasons (2009/10 and 2010/11). At initial capture, 76 animals were antiRVFV antibody positive, and were not included in the longitudinal study. However of these 76 RVFV positive individuals, there was significant geographic variation in the South, with individuals in the Crocodile Bridge (herd prevalence=36.3\%) area having a higher probability of being seropositive at initial capture than animals in the Lower Sabie area (herd prevalence $=10.3 \%)(\mathrm{Z}=17.34, \mathrm{p}<0.0001)$.

\section{Discussion:}

Geographic patterns. The geographic differences in prevalence of anti-RVFV antibody in the KNP were pronounced in the parkwide sample year of 1998. Herd seroprevalence was significantly higher in the South and Central regions. One possible explanation for the lower seroprevalence in the North is a lower density of competent mosquito vectors as a consequence of lower rainfall (Venter et al, 2003), or landscape and vegetation differences. RVFV transmission occurs principally through mosquito vectors (Pepin et al, 2010), and surveys have shown that suitable Aedes and Culex mosquito species are common in the KNP (Jupp, 1996; Alan Kemp, personal communication), but little is known about vector distribution and density in the different regions. Another unlikely possible cause for the geographical variation is reduced host population density in the northern part of the park (Owen-Smith \& Ogotu, 2003), although mosquito-borne diseases are thought to be relatively unresponsive to host population changes because vector-biting behavior is largely independent of host population density (Anderson \& May, 1986).

The possibility that buffalo in the north region are less susceptible to RVFV even if exposed at the same rate is also unlikely. Buffalo from the north are not isolated from the south and central regions, and despite the rivers used to define the geographic regions, buffalo from populations in all three regions occasionally intermix (Cross et al 2009). There 
is limited data on immune function or genetic profile of buffalo in KNP or elsewhere, however it has been suggested that there may be variation in innate immunity between herds in the South (Beechler et al, 2012), as well as in RVFV seroprevalence though this has not been linked to disease susceptibility. There is circumstantial evidence in livestock of breed differences in susceptibility to RVFV, and inbred strains of rats vary in the outcome of exposure to infection, but there is no evidence that susceptible species can become refractive to the extent that they fail to develop a detectable immune response to infection (Swanepoel and Coetzer 2004).

Within the south region of the KNP, the 2008-2010 data show that individual buffalo in the Crocodile Bridge area had a higher probability of being seropositive for RVFV than individuals in the Lower Sabie area. The home range of these two buffalo herds overlap two separate river systems, and in 2008 an outbreak of RVFV was detected in an intensive buffalo breeding facility, and in livestock and humans outside the KNP along the Crocodile River that forms the southern boundary of the park (Archer et al, 2011; Grobbelaar et al, 2011). The Crocodile Bridge area of the KNP lies on the boundary where the outbreak occurred, and hence it is likely that the difference in overall serostatus between Lower Sabie and Crocodile Bridge is a result of the localized outbreak of RVFV on the Crocodile River boundary in 2008.

Age and sex patterns. In evaluating the entire data set for 1996-2007, it is evident that older buffalo are more likely to test positive for neutralizing antibody to RVFV. Circulation of neutralizing antibody to RVFV in domestic ruminants is long lasting, possibly lifelong (Swanepoel \& Coetzer, 2004), and hence it is logical that there is a cumulative prevalence of antibody in buffalo with increasing age. There was no evidence of gender bias in seropositivity.

Evidence for interepidemic infection. The main objective of this study was to seek evidence that buffalo were being infected and seroconverting during interepidemic periods. In most years some young buffalo tested seropositive (Figure 4), despite no known outbreaks in Kruger National Park. The only survey years in which young buffalo did not test RVFV seropositive were 2006 and 2007, both of which were restricted to the Northern region of KNP where RVFV seroprevalence is significantly lower. In the Central and South regions seropositivity in animals between 0.5 years and 1 year of age occurred nearly annually; however these data were temporally and geographically scattered, making it unlikely that infection was associated with large-scale undetected epidemics. Additionally, 
five seroconversions were recorded in the Crocodile Bridge and Lower Sabie areas during the wet seasons of 2008/9, 2009/10, and 2010/11, and no known RVF outbreaks occurred in or within 80 kilometers of Kruger National Park during these periods. These results provide evidence for undetected circulation of RVFV in buffalo and possibly other wildlife species during interepidemic periods. Similar conclusions were reached by Labeaud et al (2011) who found African buffalo seroconverting outside any known outbreak of RVF. However, the results presented here make an even stronger case for interepidemic transmission of RVFV in buffalo, since the diagnostic assay we used (virus neutralization) is more specific for RVFV than the hemagglutination-inhibition assay used in Labeaud et al (2011). The hemagglutination-inhibition assay (HAI) may produce false positive results if sera contain antibody to phleboviruses that are antigenically similar to RVFV. Moreover, a diagnostic cut-off value for HAI, indicating RVFV infection has not been established for buffalo making Labeaud's results challenging to interpret. On the other hand, virus neutralization is the gold standard for detecting RVFV antibodies (McIntosh, 1980; Swanepoel et al, 1986), with specificity near 100\% (NICD, unpublished data).

Antibodies to RVFV have been found in many other wildlife species, including, but not limited to, impala, kudu, Thomson's gazelle, gerenuk, bushbuck, waterbuck, white and black rhinoceroses, and elephant (Davies, 1975; Anderson and Rowe, 1998; FischerTenhagen et al., 2000; Paweska et al., 2005; Evans et al., 2008; Paweska et al., 2008; Paweska at al., 2010), and the disease was confirmed in a waterbuck found dead in the Klaserie Nature Reserve in 1999 (NICD, unpublished laboratory records, 1999). It is notable that the genetic lineage of RVFV found in aborted buffalo fetuses in Skukuza and in the dead waterbuck in Klaserie in 1999, was the same as that which appeared in captive buffalo, farm animals and humans along the Crocodile River outside the KNP in the wet season of 2008, and also in captive buffalo outside the KNP to the north of Klaserie in the same year (Grobbelaar et al, 2011). However to the authors' knowledge no extensive surveys of RVF incidence in livestock surrounding KNP have been performed. The same virus spread to farming areas in the northeast of South Africa in 2008, representing the first occasion on which RVFV had been recorded on the interior plateau since 1976, and in the following year it appeared to the south in KwaZulu-Natal Province (Grobbelaar et al, 2011). In 2009-2011, a different lineage of RVFV, which had first been encountered in the Caprivi Strip of Namibia in 2004, spread widely in the central interior of South Africa during a succession of exceptionally wet years (Grobbelaar et al, 2011). Thus, not only was there evidence of 
protracted circulation of RVFV in a major wildlife conservation areas, but also presumptive evidence of spread of the virus to adjacent farming regions. This emphasizes the importance of understanding RVFV interepidemic cycling in wildlife populations, and investigating what other wildlife species may be involved in the sylvatic cycle. Although we demonstrate that there is likely undetected interepidemic cycling of RVF within buffalo populations, it is at a very low rate. Further investigations into whether this level of transmission in buffalo is sufficient to maintain RVF during interepidemic periods are necessary. Further studies examining whether hosts or vectors drive the geographical patterns of this disease are also needed to fully understand RVFV ecology in Kruger National Park.

\section{Acknowledgements:}

We would like to thank Kruger National Park Veterinary Wildlife Services for assistance provided during the course of the study and the technicians on the 4-year longitudinal study - Robert and Johannie Spaan. We also would like to thank Professor Peter Howell for the background work, which initiated this study of RVF in Kruger National Park. This work was supported in part by a National Science Foundation Ecology of Infectious Diseases Grant (NSF DEB-1102493/EF-0723928 and EF-0723918). Brianna Beechler is supported by a Morris Animal Foundation Fellowship.

\section{Literature Cited}

Anderson, E.C. and Rowe, L.W. 1998: The prevalence of antibody to the viruses of bovine virus diarrhoea, bovine herpes virus 1, Rift Valley fever, ephemeral fever and bluetongue and to Leptospira sp in free-ranging wildlife in Zimbabwe. Epidemiology and Infection. 121, 441-449.

Anderson, R.M. and R.M.May. 1986: The invasions, persistence and spread of infectious diseases within animal and plant communities. Philosophical Transactions of the Royal Society B 314, 533-570

Archer, B.N., J. Weyer, J. Paweska, D. Nkosi, P. Leman, K. San Tint and L. Blumberg. 2011: Outbreak of Rift Valley fever affecting veterinarians and farmers in South Africa, 2008. South African Medical Journal 101 (4), 263-266.

Barnard, B.J. and M.J. Botha, 1977: An inactivated Rift Valley fever vaccine. Journal of the South African Veterinary Association 48(1), 45-48.

Beechler, B.R., H. Broughton, A. Bell, V.O. Ezenwa and A.E. Jolles, 2012: Innate immunity in free-ranging African buffalo (Syncerus caffer): Associations with parasite infestation and white blood cell counts. Physiological and Biochemical Zoology 85(3), 255-264. 
Chevalier, V. S., T. de la Rocque, L. Baldet, L. Vial and F. Roger, 2004: Epidemiological processes involved in the emergence of vector-borne diseases: West Nile fever, Rift Valley fever, Japanese Encephalitis and Crimean Congo haemorrhagic fever. Revues in Science and Technology office of international epizootics 23(2), 537-555.

Chevalier, V.S., M. Pepin, L. Plee and R. Lancelot, 2010: Rift Valley Fever - a threat for Europe? EuroSurveillance 15(10), 1950-1956.

Cross, P.C., D.M. Heisey and J.A. Bowers, 2009: Disease, predation \& demography: assessing the impacts of bovine tuberculosis on African buffalo by monitoring at individual and population levels. Journal of Applied Ecology 46, 457-465.

Daubney, R., J.R. Hudson and P.C. Garnham, 1931: Enzootic hepatitis or Rift Valley fever: an undescribed virus disease of sheep, cattle and man from East Africa. Journal of Pathology and Bacteriology 34, 545-79.

Davies, F.G., 1975: Observations on the epidemiology of Rift Valley fever in Kenya.Journal of Hygiene 75, 219-230.

Evans, A., F. Gakuya, J.T. Paweska, M. Rostal, L. Akoolo, P.J. VanVuren, T. Manyibe, J.M. Macharia, T.G. Kziazek, D.R. Feiken, R.F. Breimen and K. Njenga, 2008:Prevalence of antibodies against Rift Valley Fever virus in Kenyan wildlife. Epidemiology and Infection 136, 1261-1269.

Fischer-Tenhagen, C., C. Hamblin, S. Quandt and K. Frolich, 2000: Serosurvey for selected infectious disease agents in free-ranging black and white rhinoceros in Africa. Journal of Wildlife Disease 36, 316-323.

Geering, W.A., F.G. Glyn Davies and V. Martín, 2002: Preparation of Rift Valley Fever contingency plans. Food and Agriculture Organization of the United Nations. Emergency Prevention System for Transboundary Animal and Plant Pests and Diseases.

Grobbelaar, A.A., J. Weyer, P.A. Leman, A. Kemp, J.T. Paweska and R. Swanepoel, 2011: Molecular epidemiology of Rift Valley fever virus. Emerging Infectious Diseases 17, 22702276.

Hamblin, C. and R.S. Hedger, 1978:Neutralising antibodies to parainfluenza 3 virus in African wildlife, with special reference to the Cape Buffalo (Syncerus caffer). Journal of Wildlife Diseases 14, 377-388.

Jupp, P.G., B.M. McIntosh, and D.L. Thompson, 1983: Isolation of Rift valley fever virus from Aedes (neomelaniconinion) circumluteolus and/or luteolateralis during an outbreak in cattle in the coastal regions of Natal, South Africa. South African Journal of Science 79, 377.

Jupp, P.G., 1996. Mosquitoes of Southern Africa. Ekoguild Publishers, Hartebeestpoort South Africa.

LaBeaud, A.D., P.C. Cross and W.M. Getz, 2011: Rift Valley Fever virus infection in African buffalo (Syncerus caffer) herds in rural South Africa: Evidence of interepidemic transmission. American Journal of Tropical Medicine and Hygiene 84, 641-646. 
McIntosh, B.M., 1972: Rift Valley fever: vector studies in the field. Journal of the South African Veterinary Medical Association 43(4), 391-395.

McIntosh, B.M. 1980: Epidemiology of Arthropod-borne Viruses in Southern Africa, DSc Thesis, University of Pretoria.

Owen-Smith, N.and J. Ogotu, 2003: Rainfall influences on ungulate population. In: DuToit, J.T., K.H. Rogers and H.C. Biggs (eds), The Kruger Experience: Ecology and Management of Savannah Heterogeneity, pp 310-331. Island Press, Washington DC.

Paweska, J.T., F.J. Burt, F. Anthony, S.J. Smith, A.A. Grobbelaar and J.E. Croft ,2003: IgGsandwich and IgM-capture enzyme-linked immunosorbent assay for the detection of antibody to Rift Valley fever virus in domestic ruminants. Journal of Virological Methods $113,103-112$.

Paweska, J.T, E. Mortimer, P.A. Leman and R. Swanepoel, 2005: An inhibition enzyme-linked immunosorbent assay for the detection of antibody against Rift Valley fever virus in domestic and wild ruminant sera. Onderstepoort Journal of Veterinary Research 70, 49-64.

Paweska, J.T., P.J. van Vuren, A. Kemp, P. Buss, R.G. Bengis, F. Gakuya, R.F. Breiman, M.K. Njenga and R. Swanepoel, 2008: Recombinant nucleocapsid - based ELISA for detection of IgG antibody to Rift Valley fever virus in African Buffalo. Veterinary Microbiology 127, 2128.

Paweska, J.T., P. Jansen van Vuren, A. Kemp, R. Swanepoel, P. Buss, R.G. Bengis, F. Gakuya, R.F. Breiman and M. Kariuki Njenga, 2010: A recombinant nucleocapsid-based indirect ELISA for serodiagnosis of Rift Valley fever in African wildlife. In: Odongo, N.F., M. Garcia and G.J. Vilioen (eds) Proceedings of Sustainable Improvement of Animal Production and Health, pp309-312. FAO, Rome 2010.

Pepin, M., M. Bouloy, B.H.Bird, A. Kemp and J. Paweska, 2010: Rift Valley fever virus (Bunyaviridae: Phlebovirus): an update on pathogenesis, molecular epidemiology, vectors, diagnostics and prevention. Veterinary Research 41(6), 61-101.

Sinclair, A.R.E., 1977: The African buffalo: a study of resource limitation of populations, University of Chicago Press, Chicago.

Singh, K.V., O.A. Osman, I.F. El Cicy and T.I. Baz, 1967:Colostral Transfer of rinderpest neutralizing antibody to offspring of vaccinated dams. Canadian Journal of Comparative Medical Veterinary Science 31, 295-298.

Swanepoel, R., J.K. Struthers, M.J. Erasmus, S.P. Shepherd, G.M. McGillivray, A.J., Shepherd, D.E. Hummitszch, B.J. Erasmus, and B.J.H. Barnard, 1986: Comparative pathogenicity and antigenic cross-reactivity of Rift Valley fever and other African phleboviruses in sheep. Journal of Hygiene, 97, 331-346.

Swanepoel, R. and J.A.W. Coetzer, 2004: Rift Valley Fever. In: Coetzer, J. and R. Tustin (eds) Infectious Diseases of Livestock. 2ndedn.pp.1037-1070. Oxford University Press, South Africa. 
Thomson, G.R., 1996: Foot and Mouth Disease in the African Buffalo.Proceedings of a Symposium on African Buffalo as Game Ranch Animal, ed. BL Penzhorn, p. 13.

Venter, F.J., R.J. Scholes and H.C. Eckhardt, 2003: The abiotic template and its associated vegetation pattern. In: DuToit, J.T., K.H. Rogers and H.C. Biggs (eds), The Kruger Experience: Ecology and Management of Savannah Heterogeneity, pp 83-129. Island Press, Washington DC.

Zeller, H.G., D. Fontenille, M. Traore-Lamizana, Y. Thiongane and J.P. Digoutte, 1997:

Enzootic activity of Rift Valley fever virus in Senegal. American Journal of Tropical Medical Hygiene 56(3), 265-272. 


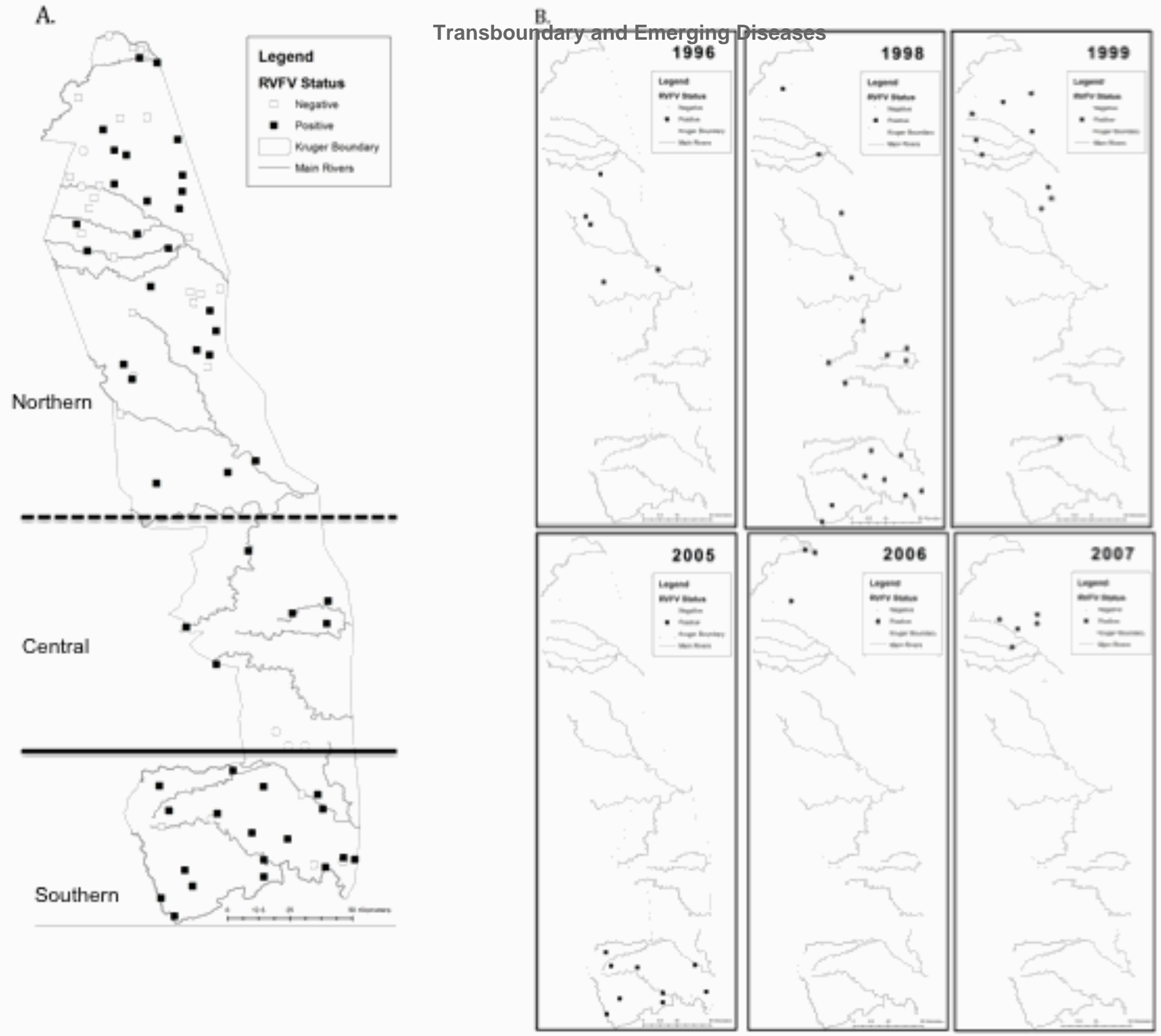

Page 14 of 19 


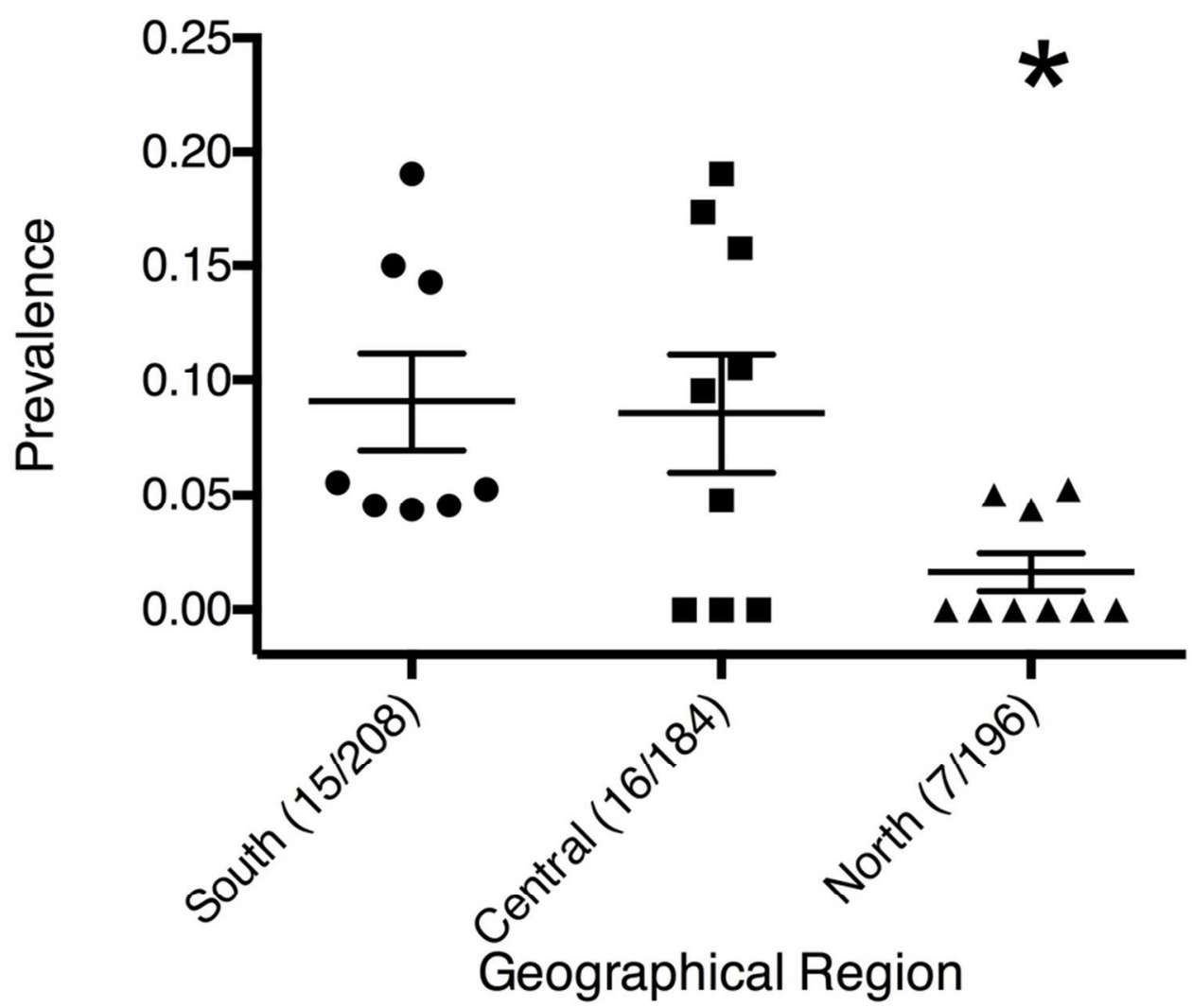

Figure 2: 1998 park-wide survey data showing that seroprevalence to RVF in buffalo herds varied by region. Each point is a herd, with prevalence noted on the $y$-axis. The centerline denotes median prevalence with standard error bars. The $x$-axis denotes the geographical region with the total positive/total number of buffalo sampled in that region in parentheses. The significant difference $(p=0.05)$ between herds appears to be driven primarily by the North region having significantly lower herd level prevalence, as noted by the asterisk on the graph. $85 \times 72 \mathrm{~mm}(300 \times 300 \mathrm{DPI})$ 


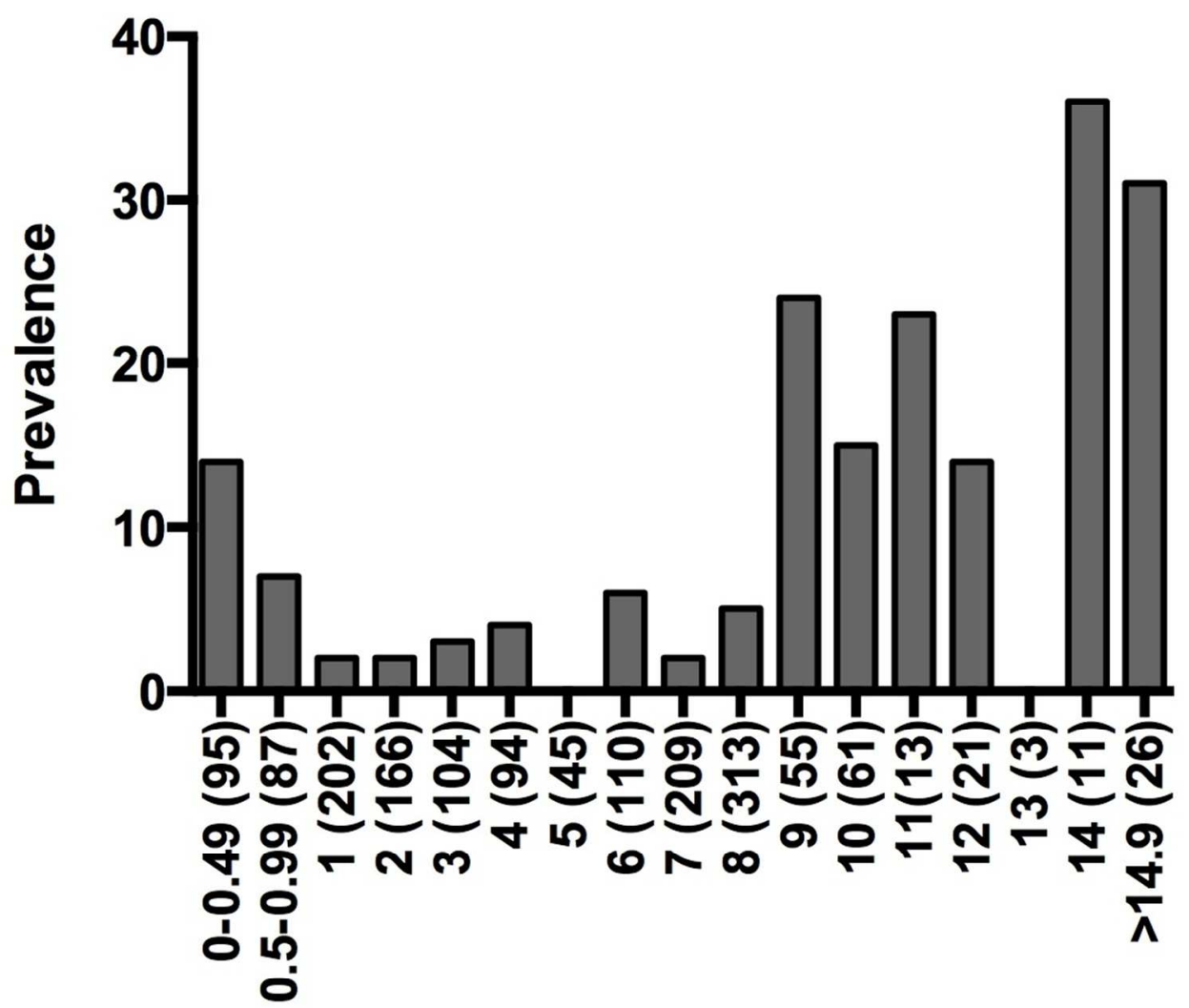

Age (sample size)

Figure 3: RVF Seroprevalence by age of buffalo. Age is shown on the x-axis and prevalence for that age category on the $y$-axis. Generally seroprevalence increases with age $(p<0.0001)$, however note the high prevalence in young calves (under 0.5 yrs of age) and older calves (between 0.5 and 1 year of age). The high prevalence in very young calves (under 0.5 years of age) is likely due to colostral transfer of antibody from their mother's at birth, where as the increased prevalence in calves older than 0.5 months indicates potential interepidemic circulation. The drop between 0.5-0.99 and 1-1.99 year olds may occur due to death of the infected calves in the prior age group.

$96 \times 87 \mathrm{~mm}(300 \times 300 \mathrm{DPI})$ 


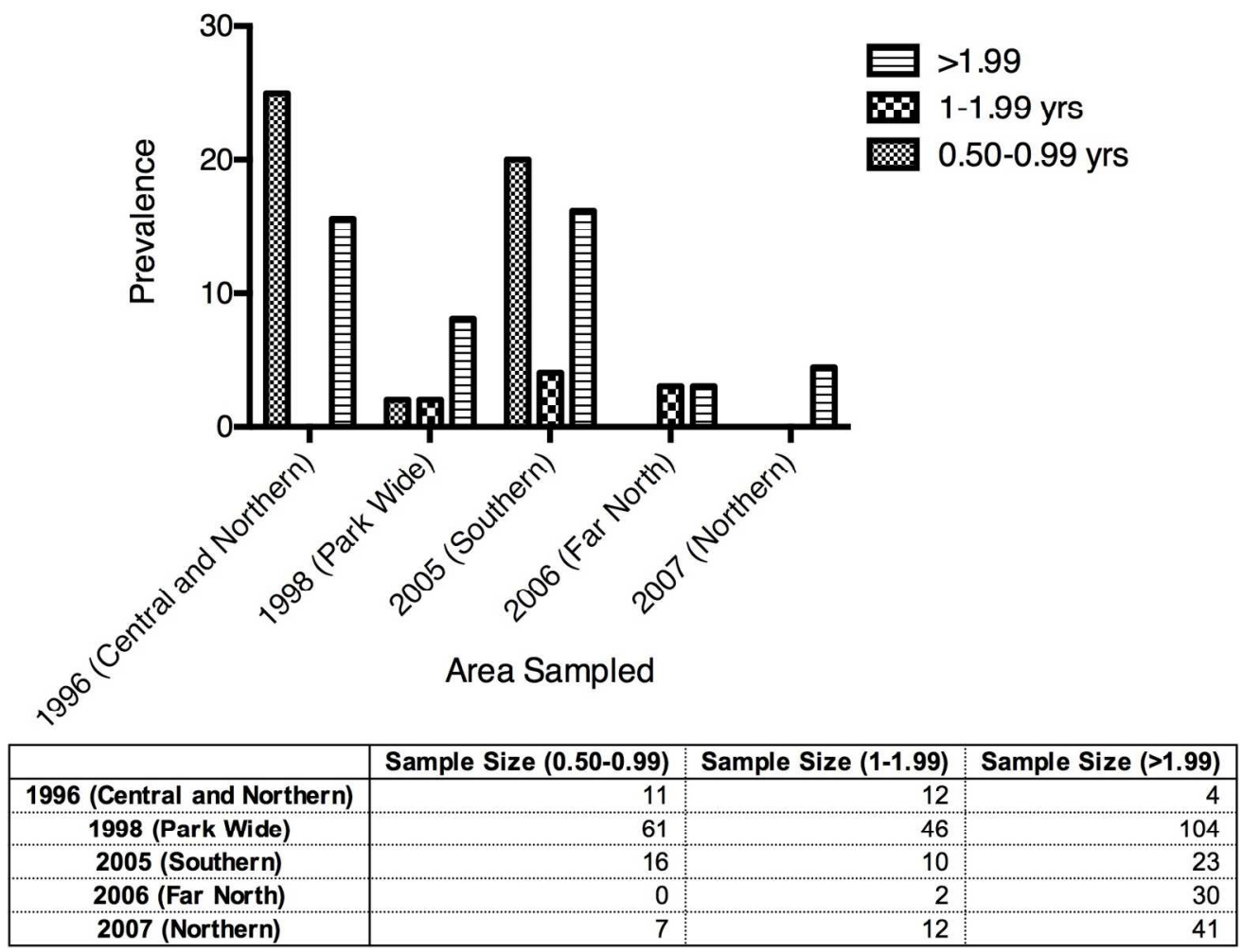

Figure 4: Seroprevalence by year and age category. Sample sizes are noted in a table below the image. Seroprevalence is noted on the $y$-axis with the x-axis being year and region of data collection. There is no data for 1999 because age classes were not quantified. In 1996, 1998 and 2005 there are calves between $0.5-1$ years of age that are RVF seropositive, indicating they must have been exposed within that year of life. $156 \times 121 \mathrm{~mm}(300 \times 300 \mathrm{DPI})$ 
Table 1: RVFV seroprevalence in herds captured between 1996-2007.

\begin{tabular}{|lllll|}
\hline Year Sampled & $\begin{array}{l}\text { Geographic } \\
\text { Area of Focus }\end{array}$ & $\begin{array}{l}\text { Number of } \\
\text { Herds Sampled }\end{array}$ & $\begin{array}{l}\text { Number of } \\
\text { buffalo } \\
\text { captured }\end{array}$ & $\begin{array}{l}\text { Number of } \\
\text { anti-RVFV } \\
\text { positive } \\
\text { herds }\end{array}$ \\
\hline $\mathbf{1 9 9 6}$ & Northern & 6 & 110 & 5 \\
\hline $\mathbf{1 9 9 8}$ & Parkwide & 29 & 588 & 18 \\
\hline $\mathbf{1 9 9 9}$ & Northern & 12 & 171 & 10 \\
\hline $\mathbf{2 0 0 5}$ & Southern & 12 & 245 & 9 \\
\hline $\mathbf{2 0 0 6}$ & Northern & 10 & 133 & 3 \\
\hline $\mathbf{2 0 0 7}$ & Northern & 13 & 229 & 5 \\
\hline Total & & 82 & 1476 & 50 \\
\hline
\end{tabular}


Table 2: The results from the generalized linear models described in the methods. Table A includes the results from the GLM performed to assess whether age and sex correlated with individual RVFV serological status in all buffalo captured between 1996 and 2007. Older animals were more likely to be seropositive, but there was no effect of sex on individual probability of being seropositive for RVF. Table B includes the results from the GLM performed on animals between 0.5 and 1 year of age, demonstrating that there was no geographical or yearly clustering among RVFV positive calves between 1996-2007.

a)

\begin{tabular}{|l|l|l|l|}
\hline & Estimate & Z-value & $\mathrm{p}$ value \\
\hline Age & 0.15 & 5.6 & $<0.0001$ \\
\hline Sex & 10.18 & 0.019 & 0.9848 \\
\hline
\end{tabular}

b)

\begin{tabular}{|l|l|l|l|}
\hline & Estimate & Z-value & p value \\
\hline Location Central (vs. North) & -0.32 & -0.26 & 0.796 \\
\hline Location South (vs. North) & 0.02 & 0.02 & 0.984 \\
\hline Year & 0.05 & 0.641 & 0.648 \\
\hline
\end{tabular}

